\title{
Determinants of Internal Audit Effectiveness (IAE) in the Ethiopian Public Enterprise, Case of Southern Region
}

\author{
Solomon Kebede Menza ${ }^{1}$ \\ MSc in Development Economics \\ Abraham Aga \\ MSc in Accounting and Finance \\ Wondwossen Jerene \\ MSc in Accounting and Finance
}

DOI: $10.7176 / \mathrm{JRDM} / 52-02$

\subsection{Introduction}

Due to political, technological and economic changes in the last decades resulted in the rise of business risks, the economic instability and the important increase of financial fraud scandals have necessitated the use of internal audit for companies (Bekiaris et al., 2013; Vinary and Skaerbaek; 2014; Tsipouridou and Spathis, 2014; Gbadago, 2015). Therefore, it is of great importance to identify the factors affecting internal audit in order to be effective. Previous studies have used different approaches to investigate internal audit effectiveness, as effective internal audit is influenced by series of factors. Moreover, factors and measurement of internal audit effectiveness have been used differently by the researchers (Arena and Azzone, 2009) and until now, there is no consensus regarding the most appropriate framework for internal audit effectiveness (Endaya and Hanefah, 2013). Thus, effectiveness of internal audit is a dynamic process and a matter of considerable debate.Public sector offices are part of the public body which is partly or wholly financed by government budget and concerned with providing basic government services to the whole society (Ministry of Finance and Economic Development (MoFED, 2004). The compositions of the public sectors are varied by their function and purposes, but in most cases, they are designed in order to enable the public sectors to achieve their goals.

The public sector provides services such as banking service, financing, education, communication service, healthcare, police, transportation, electric services, security and so on, which benefit all of the society and encourage equal opportunity to benefit from those services provided (Mihret and Yismaw, 2007). This research was focused on the determinants of Internal Audit Effectiveness in SNNPR Public sector office found in Hawasa mainly regional government offices. Mostly, the efficiency and effectiveness of the management operations in public sector are ensured by the effectiveness of its employees. Internal audit which are the focus of this study and also the key employee of public offices, are expected to work independently and objectively to enhance high quality of public services, achieve good internal control system, avoid corruption, ensure good corporate governance system, promote accountability and greater transparency (Coram et al, 2008; Van Peursem 2005; Belay, 2007).

Therefore, it is important to have effective internal audit unit as part of modern governance system in public sector offices. In corporate governance internal audit (IA) issue has received increasing attention in recent years, due to different reasons. To mention some of them, internal audit links to the internal control-risk management system; improve organizational efficiency and effectiveness through providing constructive criticism and recommendations about organizations status; reduce information asymmetry during decision making; serves as an important internal assurance in the business and financial reporting process of corporations (Soh and Bennie, 2011; Cohen and Sayag,2010; Mihret and Yismaw, 2007).

Additionally, in the accounting profession, audits play an important role in serving the public interest by increasing the accountability of managers and reinforcing trust and confidence in financial reporting process and they serve as an important link in the business and financial reporting process of corporations and not for profit providers at organizational level (Reynolds, 2009). In connection with this, internal audit identifies weak links in the system as well as creates potential opportunities for improvement and act as a feedback mechanism for the top management. Hence, organizations seeking a suitable and effective quality management system need to conduct internal audits to ensure that the system functions as intended (Lindow and Race, 2002).

Moreover, the Institute of Internal Audit's (IIA, 2004), board of directors defined internal audit as: An independent, objective assurance and consulting activity designed to add value and improve an organization's operations. It helps an organization accomplish its objectives by bringing a systematic disciplined approach to evaluate and improve the effectiveness of risk management, control, and governance processes." In addition to this (IIA) describes internal auditing as an independent activity that helps organizations to improve their operations

\footnotetext{
${ }^{1}$ Mr. Solomon is currently a PhD. Candidate of Economics in Arba Minch University
} 
(IIARF, 2013). In this regard, the internal audit function (IAF) can be considered effective when organizations follow their internal audit objective advice for improvement.Internal auditing (IA) serves as an important link in the business and financial reporting processes of corporations and not-for-profit providers (Reynolds, 2000). Internal audit play a key role in monitoring a company's risk profile and identifying areas to improve risk management (Goodwin-Stewart and Kent, 2006). The aim of internal auditing is to improve organizational efficiency and effectiveness through constructive criticism. IA has four main components: (1) verification of written records; (2) analysis of policy; (3) evaluation of the logic and completeness of procedures, internal services and staffing to assure they are efficient and appropriate for the organization's policies; and (4) reporting recommendations for improvements to management (Eden and Moriah, 1996).

In the recent years, internal auditing (IA) has undergone dramatic changes that have extended its area of involvement in a way that allow it to add more value to a company. Traditionally, the role of IA has focused on compliance assurance, financial control and assets safeguarding. After the corporate financial discussion of the 2000's, many reforms (Sarbanes-Oxley Act 2002; Combined Code 2003; OECD 2004; IFAC 2006) have reinforced the responsibilities of IA in enhancing corporate governance mechanisms. Therefore, IA has become a value creator improving the effectiveness of risk management, control and governance systems (Bou-Raad 2000; Roth 2003; Hass et al. 2006; Cohen et al. 2010).

Through the extended role of IA, internal audit has become an essential monitoring mechanism in corporate governance along with the external audit, audit committee, and executive management (Gramling etal. 2004). The aim of IA is to assist an organization in achieving its objectives (Roth 2003; Hass et al. 2006). For this purpose, IA can perform a wide variety of activities in the form of assurance or consulting services. First, it can provide assurance that the organization's systems of control are designed properly and operate effectively. Second, it can act as a management consultant to improve risk management (Spira \& Page, 2003). Third, it can assist the audit committee and external audit in monitoring the internal control system (Goodwin 2003).it can reduce fraud, misappropriation of assets and misreport financial information (Coram et al. 2008). Briefly, the internal audit function (IAF) is the cornerstone of the corporate governance, which contributes to improving the productivity, efficiency and performance of the company in both private and public sector (Mihret et al. 2010; Gros et al. 2016).

Even though, the internal audits have many roles and contributions to the organization and the public interest, it also faces many challenges from the organization they work. Some of the challenges identified by the Ministry of Finance and Economic Development (2004), in their internal audit manual are lack of management respect, lack of independence, assigned of internal auditors to many tasks and being ignored (conflict of interest) and lack of professional development.

In addition, Mihret and Yismaw, (2007) in their case study on Ethiopian public Universities, they argue that internal audit recommendations are not afforded enough management attention and support which adversely affect the effectiveness of internal audit. Moreover, lack of mechanisms in place to follow up the implementation of internal audit recommendations; absence of strategic plan and consistent documentation styles for audit work, lack of resources, poor leadership for internal audit function (IAF), absence of appropriate framework to measure IAF performance, and lack of competent personnel are also some challenges of internal auditors (Mihret and Yismaw, 2007; belay, 2007).

Therefore, the objective of this paper is to provide a review of the evolving literature on internal audit in order to highlight gaps in knowledge and make recommendations for future research. And additionally, this study contributes to the literature in two important ways. First, study to measure internal auditing effectiveness in the SNNPR regional public sectors and second, study was identified factors that could determine the effectiveness of internal audit. This study will be interesting to governance bodies and regulators in Ethiopian.

\subsection{Statement of Problem}

An effective internal audit function is a significant player in two basic governance activities; monitoring of risks and providing assurance regarding controls. Furthermore, internal audit function plays a key role in compliance work and may also spend considerable time on consulting or operational-oriented work, with the objective of enhancing the organizations effectiveness and efficiency; and all these elements map directly in to organizational governance (Hermanson and Rittenberg, 2003).

The government is aware that effectiveness of financial management will lead to the success of Government programs and activities. Therefore, to further enhance the credibility of Public Financial Management, the government has established the Internal Audit (IA) Unit in many government departments and agencies by the virtue of issuance of (Ethiopian Federal proclamation no 13/1987and office of Audit general 1997). This circular indicates the requirement of the establishment of IA unit and governing the tasks and responsibilities of internal auditing in the public sector and as an internal control mechanism in government agencies to look into the financial management integrity and value for money expenditure to the government program and activities.

According to the reports of the (SNNPRG PEFA, 2010) Unnecessary spending of public money and serious violation of financial rules, regulations, procedures and the lack of good governance due to corruption practices. 
Specifically, such as improper payment made for equipment not supplied, work not done and services not rendered equipment purchase at higher cost than market price, procurement not done according to established regulations and misuse of public money for their personal welfare. Has been highlighted by South Nation Nationalities and people's regional government Public Expenditure and Financial Accountability Assessment report (PEFA). Thus, the role of IA unit is to determine that internal control is in place by reviewing policies and practices in the organization in order to avoid loss of financial resources, non-compliance activities and also to provide reasonable assurance that public money has been spent in an efficient and effective manner. Based on the government emphasize on IA function, Audit services also can help organization for the success of better financial management in public service by playing the effective and efficient roles to promote better governance in managing public money.

The research examined on what factors that affect to the effectiveness of IA in order to perform their duties effectively and indirectly can assist the public sector in managing the public resources efficiently and preventing the violation of rule and regulation. Factors such Sufficient Resources of IAD, Independence of IAD, Competence of Staffs, Audit Experience, Management support, Relationship between Internal and External Auditors and Approved internal audit charter may be the causes of the IA effectiveness.

So many studies are conducted regarding the effectiveness of internal audit especially in developed countries influence factors of internal audit effectiveness such as maturity, size, stakeholder support, budget, competence, and reporting lines influence internal audit effectiveness (Lenz and Hahn, 2015). In this line, the literature has also outlined the growing importance of an effective internal audit for quality corporate governance (Messier, Reynolds, Simon, and Wood 2011, Prawitt, Sharp, and Wood 2011; Ramachandran, Baharud-din, Shokiyah, and Ibrahim, 2014) to some extent there are also studies in Ethiopia context (Mihret and Yismaw, 2007; Guruswamy, 2012; Mebratu, 2015; Mihret, 2010; Hailemariam, 2014). An Ethiopian public university case study in which they use determinate factors which influence the internal audit effectiveness like internal audit quality, support of management, organizational setting and attributes from auditee towards determining the internal audit effectiveness and used Questionnaire, interview and documentation for research instrument and finally found that internal audit effectiveness is strongly influenced by internal audit quality and support from management, whereas organizational setting and attributes of the auditee do not have any strong impact on audit effectiveness. As the literature reviews show, there are positively relationships between the management support and audit quality with IA effectiveness (Mihret, 2010; Hailemariam, 2014). They recommended future research to consider different factor models that may impact quality of internal audit and improve corporate governance. From this recommendation, the current study focuses on investigating the association between variables and also researcher personal motivation to study this topic. First to know what will be happen when the positively or negatively change of independent variables on dependent variable, second to now the change if government or public sectors given attention on IA effectiveness.

\subsection{Research Questions}

The study aimed at answering the following research questions,

- Are the internal audit department/staffs competent enough to perform the audit activities?

- Are the internal audit department/staffs in SNNPR public enterprise organization independent?

- Are the internal audit department in SNNPR public enterprise allocates sufficient resources based on the size of department?

- Are the internal and external auditors smoothly communicate to each other?

\subsection{Objective of the study}

The general objective of this study is to investigate determinants of internal audit effectiveness in the Ethiopian public services offices. While the specific objective of this study is:

- To assess the independence of auditors on the effectiveness of internal audit in public sectors

- To examine level of competence of auditors on the effectiveness of internal audit in public sectors..

- To examine the effect of relationships between internal and external auditors for internal audit effectiveness.

- To examine the resources and size of internal audit department in public sectors

\subsection{Scope of the Study}

This study was conducted public enterprise offices within Southern Ethiopia regional government. Since the study was based on previous researcher suggestion and comment on same topic, only public enterprise which had been selected purposively based on criteria of financial activity and administrating huge amount of annual budget was qualified to participate in the study. These major public enterprises in Southern Ethiopia regional state are namely Bureau of Finance and Economic development, microfinance institution, south regional tax authority, Health office, Educational office, trade and industry office, water construction office, road construction office were therefore 
chosen.

\subsection{Empirical Literature Review}

Ali et al. (2007), for example, stated that the most intensive problem for internal audit is coping with lack of sufficient resources. Another study by Ahmed et al. (2009) reported that, according to respondents, "fewness of internal auditors and insufficient funding" was the main reason limiting the success of internal audit performance in Malaysian governmental organizations. They suggested that with strong management support, internal audit department should have access to sufficient human resource and financial resources needed to enable employees successfully meeting their responsibilities.

Other Studies have established that the effectiveness of internal audit work is likely to be higher when the department is well resourced and sufficient number of staffs is involved in audit work (Ali et al., 2007; Alzeban $\&$ Gwilliam, 2014). The link between a sufficient number of staff and ability of an IAD to perform its duties is well documented (Brierley et al., 2001, 2003; Mulugeta, 2008; Obeid, 2010; Alzeban \& Gwilliam, 2014). Since the number of staffs in an IAD most often correlates with the size of the organization, the researcher expects that regional organizations to have a sizeable number of internal audit staff to engage in internal assurance. The number of staffs affects the scope of work and resources and time allocation. Additionally, the audit activity must have sufficient resources relative to the size of its audit responsibilities. This important variable should not be left under the control of the organization under audit, because the budget affects the audit activity's capacity to carry out its duties and responsibilities (IIA: 2006). In generally a resource can serve as a powerful planning tool for internal audit to accomplish their objective in efficiently and effectively manner. Perhaps the most obvious benefit of sufficient resource is it allows internal audits to effectively monitor its duties and responsibilities. In doing so, organizations can better guard against fraud and other potentially devastating financial risks, while Insufficient resources would create a significant barrier to fulfilling the roles and responsibilities of the internal audit activity in public sector (IIA, 2012).

The financial literature identifies independence or objectivity as key elements in ensuring effectiveness of IAD within public sector organizations (CIPFA, 2003). The Chairman of the American Institute of Certified Public Accountants (AICPA) had earlier stated independence as one of the most precious assets and the main cornerstone of the accounting profession (Mednick, 1997). Alzeban and Gwilliam (2014) also confirm that increasing weight is now being placed on the need for internal auditors to be independent and objective, even though they are normally employees of organizations. They stated lack of independence as the main obstacle to satisfactory internal audit performance in a number of developing countries (Alzeban \& Gwilliam, 2014). An example includes the case of the South African public sector, where Schyf(2000) noted a lack of independence of internal audit as a concern facing the internal audit activities in that country. The above evidence therefore suggests the importance of independence of IAD in ensuring its effectiveness within public sector organizations. To ensure independence and thus objectivity of IAD, it is now being recommended that the IAD should hierarchically not be positioned under parts of the organization that are themselves subject to internal audit scrutiny. It is suggested that IAD should have a reporting line that makes it independent of management in order to achieve independence (Schyf, 2000). In Ghana, the internal audit units/departments within the MDAs are required to submit reports on their activities to the audit committee of the board of directors.

Staff competence is an important key to the effectiveness of the internal audit activities (Al-Twaijry et al.2003; Alzeban \& Gwilliam 2014). The International Standards for the Professional Practice of Internal Auditing (ISPPIA) highlights the importance of internal audit team who possesses the knowledge, skills, and other competencies necessary to perform their responsibilities (ISPPIA, Standard 1210). Indeed, internal auditors must collectively have the necessary education, professional qualifications, experience and training to be able to add value and improve the organization's operations (Mihret \& Woldeyohannis 2008; Ali \& Owais 2013). Additionally, internal auditors require good interpersonal skills in communication, persuasion, collaboration, and critical thinking to effectively fulfill their duties (Smith 2005; Fanning \& Piercey 2014). Furthermore, external auditors use competencies as a critical criterion to evaluate IA performance (Al-Twaijry et al. 2004; Abbass \&Aleqab 2013).

Previous studies suggest that competence of internal auditors is a critical determinant of IA effectiveness (Albrecht et al. 1988; Van Gansberghe 2005; Al-Matarneh 2011). In the Saudi environment, Al-Twaijry et al. (2003) noted that the adequate level of competencies of internal audit staff in terms of training, experience, knowledge, and professional qualifications have a positive influence on the effectiveness of IA.

Similar results were obtained in other studies conducted in Malaysia (Ahmad et al. 2009), Iran (Alizadeh 2011) and South Africa (Staden \& Steyn 2009). Furthermore, Ziegenfuss (2000) ranked the auditor education levels, the staff experience, the percent of certified staff and the training hours per internal auditor among the most important inputs of the internal audit performance. In Taiwan, Hung \& Han (1998) found that the training and professional abilities of internal auditors positively and significantly affect the progress of annual auditing plan.

Moreover, Abdolmohammadi (2009) has demonstrated that certified internal auditors improve the compliance with the ISPPIA in Anglo-Saxon countries. Other studies suggest that lack of competence of internal 
auditors is an obstacle to the effectiveness of IA in a number of African countries as Ethiopia, Ghana and Kenya (Mihret \&Yismaw 2007; Onumah \& Yao Krah 2012; Walter \& Guandaru 2012).

The qualification of the IA staff, especially those that are certified internal auditors, is also important. Certified and experienced staff members can have very good knowledge of the operations and systems of the institutions, thus helping to reduce risk and to set proper audit scope of activities. The role of an internal audit in an institution is to ensure that the organization adheres to all financial, personnel, lending, data processing, and other administrative policies and

Procedures as well as economy, efficiency and effectiveness with which resources are used (IIA, 2002). Moreover, for a longer period of time, behavioral researchers give more concerned on the effects of experience particularly in the aspect of decision making in a highly important fields such as auditing (Ahdolmohammadi \&Wright, 1987; Wright \& Wright, 1997). Mann \& Norman, 2006) because audit professional practices through audit experience influenced their audit professionalism and this have significant impact on their audit efficiency and effectiveness (Intakhan \& Ussahawanitchakit, 2010). In line with the above, recently, research in the area of professional experience in accounting and auditing are increasing (Gaballa \& Ning, 2011) and due to this development, the impact of audit experience on earnings quality and perceptions of earnings quality has been the focus as the area of research in the United States (Chi, Myers, Omer, \& Xie, 2010) additionally, investors in China perceive earnings to be more credible especially when it's audited by more experienced auditors (Wang, Yu, Zhang \& Zhao (2012). Virtually this should also be an area of research in the public sector organizations context.

Top management support is crucial to the acceptance and appreciation of the IAF within an organization. (ISPPIA, standards 1409 and 1609) states that internal audits should be supported from top management and Board of Directors to execute its duties and fulfill its responsibilities. Indeed, the internal audit department should have sufficient resources to improve the effectiveness of its activities.Previous studies have demonstrated that support for internal auditors by top management is critical to the effectiveness of IA. Albrecht et al. (1988) found that management support was the most important determinant of IA effectiveness within the American private sector. In Taiwan, Hung \& Han (1998) found that favorable management's attitude toward internal auditors contributes to the progress of annual auditing plan and therefore to the effectiveness of IA.

Reporting on the Malaysian public sector, Ahmad et al. (2009) indicated that management support has a considerable influence on the implementation of internal audit recommendations and the internal auditors would be well supported by any means. Cohen \& Sayag (2010) found that management support was strongly related to the three auditing effectiveness dimensions (auditing quality, audit evaluations, and added contribution of IA) in Israeli organizations. Alzeban \& Gwilliam (2014) found that management support was the most important factor influencing IA effectiveness within the Saudi Arabian public sector organizations. They noted that IA effectiveness would be enhanced by hiring trained and experienced staff, and providing sufficient resources.Furthermore, Mihret \& Yismaw (2007) found that management support was the second most important factor influencing IA effectiveness within the higher educational institution in Ethiopia, after internal audit quality. In a survey of Ghanaian internal auditors, Onumah \& Yao Krah (2012) found that IA effectiveness was mainly hindered by the absence of management support for the internal audit department. Top management must be truly aware of the importance of the role of IA within an organization and fully support the internal audit staffs to ensure legitimacy, credibility and authority of the IAF (Van Gansberghe2005; Sarens \& De Beelde 2006).

For a good relationship to exist between internal and external auditors, the independence of the internal audit department is critical. More often than not, external auditors rely on the work of internal auditors to do their job. The scope of work and materiality of systems and structures depend on the efficiency and effectiveness of the internal audit function. For instance, a poorly deployed internal auditing system can lead to increased, non-valueadded costs, many hours of wasted resources and eventual breakdown of the assurance system of the institution. The chief internal auditor also needs to coordinate their activities to assure that all affairs are covered sufficiently, and any possible rework is at the lowest level. The significance of coordination and participation between inner examiners and external inspectors has for some time been considered as advantages of inside audit for the association, and external partners. Examples incorporate joint planning and correspondence of data, sentiments, and reports with a specific end goal to encourage astounding audits, including aversion of pointless revamps (Almohaimeed, 2000). ISPPIA, standards guidelines have demonstrated that collaboration in the middle of inner and external auditors ought to incorporate sharing data and coordination of activities. Applying these standards requires proficient interchanges in the middle of inside and external auditors which thusly help internal auditors in achieving their goals and giving better administrations. From external auditors' perspective, data acquired by inside auditors will probably help creating a superior audit sentiment, and likely in situations where outer auditors can depend on the work done by inner auditors, efficiency can likewise be made strides.

Brierley et al. (2001) demonstrated that proper participation can enhance productivity and adequacy of audits, and helps administration give higher quality administrations. Trouble in the middle of inner and external auditors is regularly perceived as a component harming the nature of both sorts of audit. According to the literature, internal auditing, when effectively implemented, becomes an important gauge as to the level of risk in the company or 
institution (Strauss, 2009). The primary function of IAD through the continuous monitoring of the institution's quality assurance system is a good feedback to external auditors in the task and scope of audit engagement.

Internal audit charter is defined by the IIA as "a formal written document that defines the activity's purpose, authority and responsibility. The charter should be (a) establish the internal audit activity's position within the organization; (b) authorize access to records, personnel and physical properties relevant to the performance of managements; and (c) defined the scope of internal audit activities" (IIA,2001). Additionally, an internal audit charter typically includes the responsibilities of the IA in broad terms, the standards followed by the IA; and the relationship between the IA and the audit committee. It may also define access to the information (documents, records, systems, and personnel) necessary to perform and reach conclusions on the work, and it is a vehicle for asserting that there are no unreasonable limitations on the scope of the auditor work. The charter should clearly identify and record any limitations and alter to actual or potential changes on internal and external conditions that affect its ability to provide internal control assurance from a forward-looking perspective (Regan, 2002). Different authors have been explained the presence of defined audit charter in organizations will helps auditors to be effective. For instance, O. Regan (2002) concludes that a well drafted charter is an important ingredient for the IA effectiveness. It helps to direct the efforts of audit staff and defines what the board can expect on the assurance it required on internal control from an IA. Van (2005) added that the presence of a strong charter adds an official and respected layer of authority to the position of IA in the company. It is also an important feature of insuring success in achieving the independent status of an IA. Furthermore, the existence of audit charter in organization influences senior management to flow the recommendations of the internal auditor (Van, 2005) which in turn affects IA effectiveness.

Along with the findings of different scholars on the internal audit effectiveness, the researcher has criticized some of previous studies like, Ahmed et.al(2009) conducted research on Malaysia public services, He consider only the people that attend symposium in 2008 and he collected and analysis data by using simple percentage method rather than using filed survey of wider groups and finally he found lack of auditors respondents which is criticized as research gap. Theophanous et al. (2011) examines the relationship between element of internal control system and internal audit effectiveness and the result of the study reveal positive relationship between the two. But the studies used only 52 Hotels from thousands of hotels in Greek as a sample size. From this study the researcher identified the research gap the sample size of 52 hotels was not representative of the total hotels in Greek. By considering this gap the researcher pay due attention during on time of selecting sample size, data collection and data analysis on this study.

\subsection{Conceptual framework.}

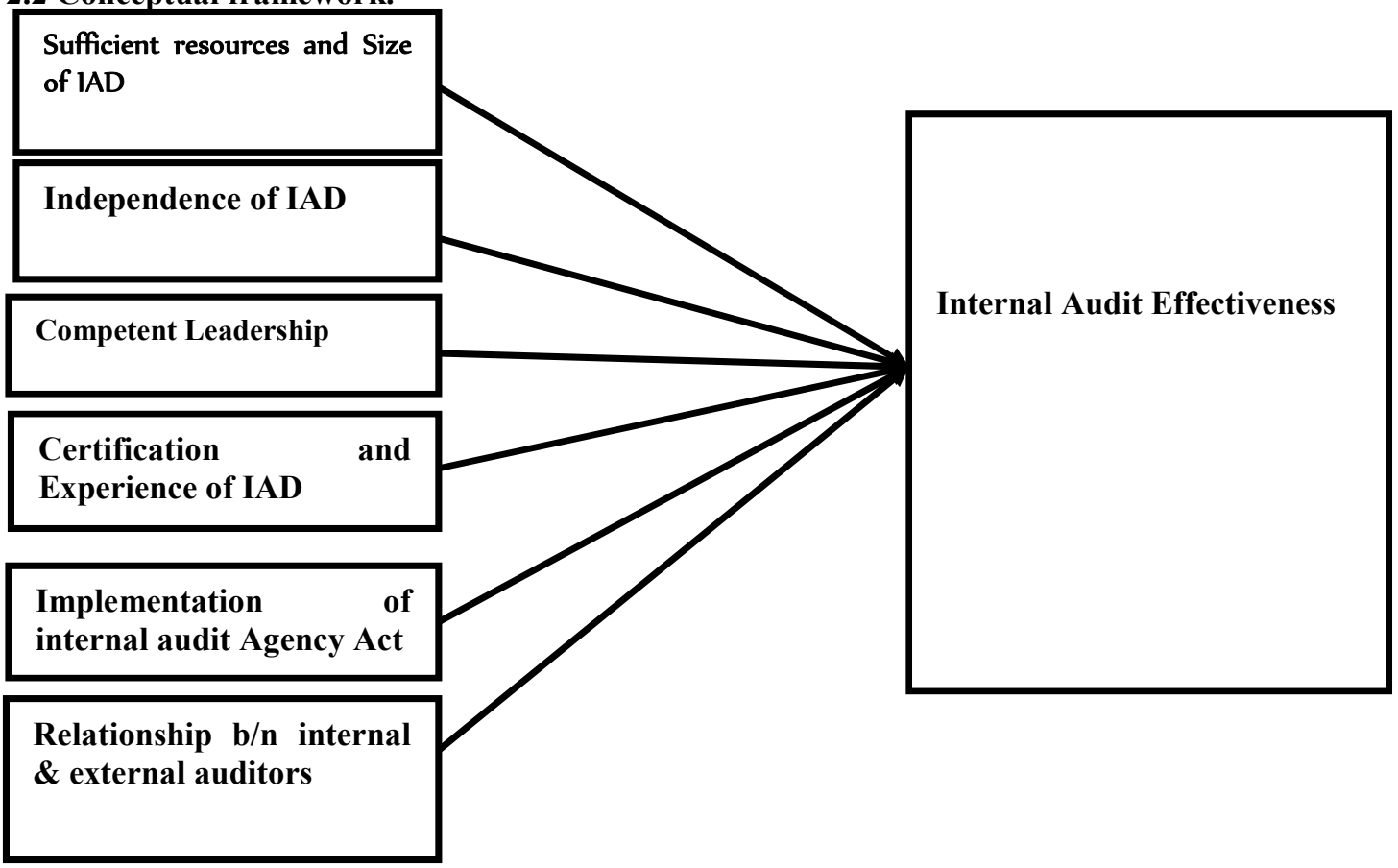

\section{CHAPTER THREE}

\section{RESEARCH DESIGN AND METHEDOLODY}

\subsection{Introduction}

This chapter is an important and used to develop an effective research design which shows the logical relation 
between the data collection, the analysis and conclusions. A good research design satisfies the most suitable methods of investigation, the nature of the research instruments, the sampling plan and the types of data (De Wet, 1997). This section specifying the study area, research design, study population, sampling size and sampling techniques, research instruments, reliability and validity measurement methods, the dependent and independent variables to be applied throughout the research, and finally the model specifications used for data analysis which are applicable and use in the study are be included.

\subsubsection{Geographical location of the study area}

Southern region is one among the 9 regions in Ethiopia.The region is located in the South of Ethiopia, sharing borders with Oromia, Gambella, Kenya and Sudan. It has a land area of 110,000 square kilometers, 10 percent of the total land area of Ethiopia. Based on the 2003/04 population and Housing Census, the population of the region was estimated at 15.7 million in 2004 , accounting for about 20 percent of the population of the country.

\subsection{Research Design}

To obtain the advantage of both the qualitative and quantitative research approach and at the same time to overcome their limitation, the mixed approach has been used.

\subsection{Types of data}

The data used to conduct this study are the primary and secondary data. Primary data gathered through the questionnaires and interviews and secondary data gathered through report. Self-administered Questionnaires were distributed to only internal audit staffs and interview held with the General Managers/Head of organization.

\subsection{Target population}

The target populations for this research were the Southern Ethiopian Regional public sector offices which are found in Hawassa city. The current data from regional Bureau of Finance and Economic Development (BOFED) 2009E.C, South National Nationality and People Regional State (SNNPR) shows that 47 government budgetary public sectors at regional level. And all of them have internal audit staffs, (SNNPR BOFED, 2009). And regional government classified public sectors in to two categories which are core processing organization and level organization based on budget administration. BOFED classified under Core processing organization and have 17 internal auditors; and level organizations are classified again in to three levels which are level (1, 2, and 3). While under level one 7 public organization are categorized and have 39 internal auditors, under level two 9 organization are categorized and have 34 internal auditors and under level three there are 31 public sectors and 78 internal auditors are found (BOFED, 2010). Thus, the target population of the study was 168 internal auditors of fortyseven public sectors of southern regional state of Ethiopia.

\subsection{Sample Techniques}

Only members of internal audit staff and head of public organization were selected for this study from the SNNPR government public sectors was sampled for this study. Other than that, studying a sample selection allows for greater accuracy of results, greater speeds of data collection, lower cost of research and availability of the population elements.

Simple random sampling technique was used to select members of the internal audit staff and heads of organization from total population. Random sampling was used to select individual members to be subjected to the study to ensure that every member of the population was accorded an equal chance of being included in the study thereby eliminating biasness.

\subsection{Sample size}

According to Mugenda and Mugenda (2008) at least 10\% of the target population is enough for a sample size. The study involved a total population of 168 internal auditors chosen from all the 47 public sectors. Respondents were chosen through simple random sampling technique. If the population is small then the sample size can be reduced slightly because a given sample size provides proportionately more information for a small population than for a large population (Anderson, Sweeny \& Williams, 2014). From the total population of 168, the total sample size was identified by using Taro Yamane's (1967:886) statistical formula with 95\% confidence level and 5\% error. Hence, the total sample size (n) was 110 and determined using the equation below.

$$
\begin{gathered}
n=\underline{N} \\
1+N(e) 2
\end{gathered}
$$

Where $\mathrm{n}$ is the sample size, $\mathrm{N}$ is the population size, and $\mathrm{e}$ is the level of confidence which we have determined as $95 \%$. When researcher uses the formula above to the population, we get the following sample sizes:

$$
\begin{aligned}
& \mathrm{n}=\frac{168}{1+168(0.05) 2} \\
& \mathrm{n}=118
\end{aligned}
$$


this sample size is proportionately distributed among levels of organizations in the public sector as shown in the table below:

\begin{tabular}{lcc} 
& \multicolumn{3}{c}{ Table 3.1: Sample Size distribution } \\
\hline Organizational categories & Population & Sample Size \\
\hline Core processing organization & 17 & 12 \\
Level 1 organization & 39 & 27 \\
Level 2 organization & 34 & 24 \\
Level 3 organization & 78 & 55 \\
Total & 168 & 118
\end{tabular}

\subsubsection{Model specifications}

The objective of analysis of internal audit effectiveness is based up on polychotomous responses as opposed to dichotomous responses models. The three most commonly used approaches to estimating binary response models are the Linear Probability Model (LPM), the Logit model and the probit model. We cannot propose the ordinary least square estimation techniques since our dependent variable is having five categorical values. The Linear Probability Model is the model, which expresses the dichotomous dependent variable (Y) as a linear function of the explanatory variable $(\mathrm{X})$. Because of its computational simplicity, LPM has been used in econometric applications especially during and before the 1960s. However, as indicated by Maddala, and Gujarati the linear probability model has an obvious defect in that the estimated probability values can lie outside the normal distribution (0-1) ranges. The fundamental problem with the LPM is that it is not logically a very attractive model because it assumes that the marginal or incremental effects of explanatory variables remain constant, that is $\mathrm{Pi}=$ $\mathrm{E}(\mathrm{y}=1 / \mathrm{X})$ increases linearly with X (Maddala, 1997; Gujarati, 1988; Amemiya, 1985). In addition, our dummies for the dependent variable takes five different value which is also the limitation of LPM.

The limitation of the linear probability model suggests that there is a need to have an appropriate model in which the relationship between the probability that an event that takes an ordered values is non-linear (Gujarati, 1988; Maddala, 1997). The authors suggested that the sigmoid or S-shaped curve, which very much resembles the Cumulative Distribution Function (CDF) of random variable, is used to model regressions where the response variable is taking polynomial responses, taking values $1,2, \ldots, 5$. The Cumulative Distributions Functions (CDFs), which are commonly chosen to represent ordered response models, are the Logit (logistic CDF) model and the Probit (normal CDF) Model. These models are termed as ordered logit and ordered probit models, yet each providing proximately same result with some technical conversions. Hence, its up to the investigator to use either of the two models.

For example, in our case we can order the response of the agents regarding their institute internal audit effectiveness as strongly disagree, disagree, neutral, agree and strongly agree, with their respective codes 1,2,3,4, and 5, respectively. The codes 1-5 mean nothing in terms of their value, just an ordering to show you the lowest to highest response rates.

Let us consider ordered logit model specification for a latent variable given as:

$$
\begin{gathered}
y_{i}^{*}=\alpha_{0}+\alpha_{1} x_{1}+\alpha_{2} x_{2}+\cdots+\alpha_{k} x_{k}+\varepsilon \\
\boldsymbol{y}_{\boldsymbol{i}}=\boldsymbol{x}_{\boldsymbol{i}}^{\prime} \boldsymbol{\alpha}+\boldsymbol{\varepsilon}_{\boldsymbol{i}} \\
\boldsymbol{y}_{\boldsymbol{i}}=\boldsymbol{j} \text { if } \boldsymbol{u}_{\boldsymbol{j}-\mathbf{1}}<\boldsymbol{y}_{\boldsymbol{i}}^{*} \leq \boldsymbol{U}_{\boldsymbol{j}} \\
\text { where } i=1,2,3, \ldots, N
\end{gathered}
$$

The probability that observation $\mathrm{i}$ will select alternative $\mathrm{j}$ is:

$$
\begin{aligned}
P_{i j} & =P\left(y_{i}=j\right)=P\left(U_{j-1}<y_{i}^{*} \leq U_{j}\right) \\
& =F\left(U_{j}-x_{i}^{\prime} \alpha\right)-F\left(U_{j-1}-x_{i}^{\prime} \alpha\right)
\end{aligned}
$$

For the Ordered logit, $\mathrm{F}$ is the logistic cumulative density function (CDF) :

$$
F(z)=e^{z} /\left(1+e^{z}\right)
$$

In our case, internal audit effectivenes which is our dependent variable takes a response from strongly disagree to strongly agree $(1,2, \ldots, 5)$. The choice rule is summarized as follows:

$$
\begin{gathered}
y_{i}=1 \text { if } y_{i}^{*} \leq U_{1} \\
y_{i}=2 \text { if } U_{1}<y_{i}^{*} \leq U_{2} \\
y_{i}=3 \text { if } U_{2}<y_{i}^{*} \leq U_{3} \\
y_{i}=4 \text { if } U_{3}<y_{i}^{*} \leq U_{4} \\
y_{i}=5 \text { if } y_{i}^{*}>U_{4}
\end{gathered}
$$

By recalling, $\boldsymbol{y}_{\boldsymbol{i}}=\boldsymbol{x}_{\boldsymbol{i}}^{\prime} \boldsymbol{\alpha}+\boldsymbol{\varepsilon}_{\boldsymbol{i}}$, we can compute the respective probabilities for the five categories as:

$$
\begin{gathered}
\operatorname{Pr}\left(y_{i}=1\right)=F\left(U_{1}-x_{i}^{\prime} \alpha\right) \\
\operatorname{Pr}\left(y_{i}=2\right)=F\left(U_{2}-x_{i}^{\prime} \alpha\right)-F\left(U_{1}-x_{i}^{\prime} \alpha\right) \\
\operatorname{Pr}\left(y_{i}=3\right)=F\left(U_{3}-x_{i}^{\prime} \alpha\right)-F\left(U_{2}-x_{i}^{\prime} \alpha\right) \\
\operatorname{Pr}\left(y_{i}=4\right)=F\left(U_{4}-x_{i}^{\prime} \alpha\right)-F\left(U_{3}-x_{i}^{\prime} \alpha\right) \\
\operatorname{Pr}\left(y_{i}=5\right)=1-F\left(U_{4}-x_{i}^{\prime} \alpha\right)
\end{gathered}
$$


Hence, our ordered logit model has been written as

$Y=\beta_{0}+\beta 1$ mang sp $+\beta_{2}$ suff fu $+\beta 3$ aud expe $+\beta 4$ ext aud asse $+\beta 5$ prof stan $+\beta 6+$ unrest acces $+\beta 7$ compe lea $+\varepsilon$

Where:

$\beta 0=$ intercept of regression line

$\mathrm{B}_{\mathrm{i}}=$ slope coefficient of the regression line

$$
\mathrm{E}=\text { error term }
$$

\section{Research Findings: Analysis and Discussion \\ 4.1. Results of Econometric Data Analysis}

\subsubsection{Econometric tests}

Before going to estimate the specified models, it is important to undertake different tests on whether the basic assumptions of the model are met or not. In addition, since the study is a cross-sectional, autocorrelation, which is a common problem in time serious data, is ruled out. Hence, the rest tests including the goodness of fit of the model should be tested as follows.

\subsubsection{Multicollinearity Test}

Multicollinearity is an inevitable phenomenon in all multivariate analysis, no matter how small or big the problem is. However, if the co-variation is strong it will affect the significance of the estimates and remedial test is necessary. Therefore the existence of multicollinearity is tested by using pair-wise (PW) correlation coefficient test for both dummy independent variables in the model. A rule of thumb is employed in characterizing the multicollinearity of variables. By the rule of thumb, if the PW coefficients are greater than 0.75 , an indicator of serious multicollinearity problem. Here in this study the coefficients of all independent variables are less than 0.75 , which is an indicator of the absence of serious multicollinearity problem (Appendix I).

\subsubsection{Model adequacy tests}

In classical estimation technique it is inevitable to check whether the model is adequate or not. So this study was used two alternative ways to test the model adequacy; namely, the likelihood ratio test for model adequacy and Ramsey Reset test for omitted variable bias. As we see from the results in Appendix III the Ramsey test result of the p-value is 0.1868 which is greater than $1 \%$ level of significance and in bias of accepting the null hypothesis, which indicates that there is no omitted variable, except by chance.

In addition, the summary statistics of the ordered logit specification on Appendix III show that the model adequately fitted the data. Very small amount of p-value shows that the model is adequate, in our case Prob $>$ chi $2=0.000$. Thus the result indicates the existence of at least one of the independent variables is significant in predicting effectiveness of internal audit.

\subsubsection{Heteroscedasticity test}

A classical linear regression model assumes constant variance of the error term. So, the error term is not expected to be heteroscedastic by the nature of the model itself, therefore we need to test for heteroscedasticity problem. As indicated in Appendix II the White's test for the problem of heteroskedasticity showed that the data have no problem of heteroskedasticity. Since the Probability - chi $2=0.3990$ is greater than $1 \%$ level of significance, we accept the null hypothesis. Hence, there is no serious heteroskedasticity problem.

\subsubsection{Normality test}

The ordered logit model assumes a standard logistic distribution rather than normal distribution. The error term is not assumed to follow a normal distribution. It is clear from the nature of the model that it is impossible to have a normal distribution with the dependent variable taking ordered values, $1,2, \ldots, 5$. Therefore, there is no need to conduct a normality test.

\subsection{The Regression Results}

The regression outcome that are obtained by regressing the internal auditors effectiveness in identifying noncompliance activities and the internal auditors ability in adding value for their organization on the competency of staff (comp), independence of internal audit department (indepen), Management Support (mgtsupp), sufficient resources (resource), Approved IA chart(Apprvchrt) and Relationship between internal and external auditors ( Rship) were analyzed and reported. Finally, the hypothesis tests were carried out based on the proposed hypothesis and the regression results.

\subsubsection{Summary of Econometrics Result}

The regression results examine the necessary indicators of the internal audit effectiveness by using the variables identified in the model. As shown below on table 4.3 regarding Model summary, all 118 observations in our data set were used in the analysis.

According to McFadden higher values of the Pseudo $\mathrm{R}^{2}$ indicates that the explanatory variables are better capturing the variation in the dependent variable. In other hand, it indicates that at least one included (independent) 
variable is significantly predicting our dependent variable; internal audit effectiveness.

\begin{tabular}{lllll}
\hline Ordered logistic & Regression & Number of obs & $=$ & $\mathbf{1 1 8}$ \\
\hline & & LR chi2(32) & $=$ & 186.20 \\
Log likelihood $=$ & -51.167517 & Prob $>$ chi2 & $=$ & 0.0000 \\
\hline
\end{tabular}

Table 4.4 Ordered logit result

Ordered Logit Result

Table _: Results for ordered logit model by taking internal audit effectiveness as dependent variable

\begin{tabular}{|c|c|c|c|c|c|c|}
\hline Iaditeffecv & Coef. & Std. Err. & $\mathbf{Z}$ & $\mathbf{P}>\mathbf{Z}$ & [95\% Conf. & Interval] \\
\hline 2.gender & 1.862969 & .76611 & 2.43 & $0.015 * *$ & .3614207 & 3.364517 \\
\hline \multicolumn{7}{|l|}{ Age } \\
\hline 2 & -.3532132 & 1.256514 & -0.28 & 0.779 & -2.815935 & 2.109509 \\
\hline 3 & -2.037121 & 1.353907 & -1.50 & 0.132 & -4.690729 & .6164873 \\
\hline 4 & -2.591407 & 1.636022 & -1.58 & 0.113 & -5.797952 & .6151372 \\
\hline 5 & -1.46479 & 2.959242 & -0.49 & 0.621 & -7.264798 & 4.335218 \\
\hline \multicolumn{7}{|l|}{ EXpr } \\
\hline 2 & -23.82487 & 2462.794 & -0.01 & 0.992 & -4850.813 & 4803.163 \\
\hline 3 & -24.09043 & 2462.794 & -0.01 & 0.992 & -4851.079 & 4802.898 \\
\hline 4 & -26.00057 & 2462.795 & -0.01 & 0.992 & -4852.989 & 4800.988 \\
\hline \multicolumn{7}{|l|}{ Educ } \\
\hline 2 & 2.718191 & 2.071424 & 1.31 & 0.189 & -1.341726 & 6.778107 \\
\hline 3 & 2.066107 & 2.005658 & 1.03 & 0.303 & -1.86491 & 5.997124 \\
\hline 4 & 4.675518 & 4.157053 & 1.12 & 0.261 & -3.472156 & 12.82319 \\
\hline \multicolumn{7}{|l|}{ Comptenc } \\
\hline 2 & .1248221 & .9416495 & 0.13 & 0.895 & -1.720777 & 1.970421 \\
\hline 3 & 2.582315 & 1.200185 & 2.15 & $0.031 * *$ & .2299959 & 4.934633 \\
\hline 4 & 3.857172 & 1.303658 & 2.96 & $0.003 * * *$ & 1.30205 & 6.412294 \\
\hline 5 & 9.022024 & 2.235336 & 4.04 & $0.000 * * *$ & 4.640847 & 13.4032 \\
\hline \multicolumn{7}{|l|}{ Indepen } \\
\hline 2 & .3753362 & 1.740269 & 0.22 & 0.829 & -3.035529 & 3.786202 \\
\hline 3 & -.0302208 & 1.765436 & -0.02 & 0.986 & -3.490411 & 3.429969 \\
\hline 4 & 5.366062 & 2.215807 & 2.42 & $0.015 * *$ & 1.023161 & 9.708964 \\
\hline 5 & 9.55824 & 3.076028 & 3.11 & $0.002 * * *$ & 3.529336 & 15.58714 \\
\hline \multicolumn{7}{|l|}{ Resource } \\
\hline 2 & -2.671906 & 1.46109 & -1.83 & $0.067^{*}$ & -5.535589 & .1917773 \\
\hline 3 & -1.993044 & 1.412942 & -1.41 & 0.158 & -4.762361 & .7762721 \\
\hline 4 & -4.588464 & 1.723456 & -2.66 & $0.008 * * *$ & -7.966376 & -1.210553 \\
\hline \multicolumn{7}{|l|}{ Rship } \\
\hline 2 & 1.01345 & 1.377024 & 0.74 & 0.462 & -1.685469 & 3.712368 \\
\hline 3 & 1.435477 & 1.496582 & 0.96 & 0.337 & -1.497771 & 4.368725 \\
\hline 4 & 4.520458 & 1.909462 & 2.37 & $0.018 * *$ & .777981 & 8.262936 \\
\hline \multicolumn{7}{|l|}{ Mgtsupp } \\
\hline 2 & .2354274 & 1.946941 & 0.12 & 0.904 & -3.580507 & 4.051362 \\
\hline 3 & 1.287832 & 2.034378 & 0.63 & 0.527 & -2.699475 & 5.275139 \\
\hline 4 & 1.368033 & 2.120118 & 0.65 & 0.519 & -2.787322 & 5.523389 \\
\hline \multicolumn{7}{|l|}{ Apprvchrt } \\
\hline 2 & -9.201267 & 5.397631 & -1.70 & $0.088^{*}$ & -19.78043 & 1.377896 \\
\hline 3 & -6.292443 & 5.279787 & -1.19 & 0.233 & -16.64064 & 4.05575 \\
\hline 4 & -7.778367 & 5.369782 & -1.45 & 0.147 & -18.30295 & 2.746212 \\
\hline 5 & 6.123036 & 1873.424 & 0.00 & 0.997 & -3665.721 & 3677.967 \\
\hline /cut1 & -34.29967 & 2462.802 & & & -4861.303 & 4792.703 \\
\hline /cut2 & -28.90629 & 2462.802 & & & -4855.909 & 4798.096 \\
\hline /cut3 & -21.23408 & 2462.802 & & & -4848.237 & 4805.769 \\
\hline /cut4 & 9.162865 & 6.692265 & & & -3.953732 & 22.27946 \\
\hline
\end{tabular}

$* * *, * *$ and $*$ indicates the variables are significant at 1,5 and 10 level of significance, respectively

Source: Survey data, 2017/18, Stata 11 output 
The ordered logit regression analysis of results presented in table 4.4 above more comprehensive and accurate examination of the research hypothesis. Therefore, the regression results obtained from the model were utilized to test these hypotheses. The hypotheses wanted to test Competency of staff (compt), Independence (indepe), Sufficient resources, Approved internal audit chart (Apprchrt) and Relationship between internal and external auditors (Rship) and Gender were significantly influence internal audit effectiveness or insignificantly which was measured in terms of internal auditors ability to identify the noncompliance activities and by adding contributions to the public organization in SNNPR state.

As can be seen in table 4.4 above the p- value for the compt, indepen, resource, Aprrchrt, Rship and Gender were statistically significant at $(p<0.01),(p<0.05),(p<0.1)$ respectively which suggests a strong support for hypothesis 1, 2, 3, 4, 5 and 6; whereas, Management support (mgtsupp) are not supported the developed hypothesis 7 because it was statistically insignificant at $(\mathrm{p}<0.05)$.

The variable competence of staff was significantly predicts effectiveness of internal audit, especially for the response category of neutral, agree and strongly agree as compared to the reference category, strongly disagree. Holding other factors constant, a unit improvement in the strongly agree competency level, we would expect a 9.02204 improvement in the log odds of being in the relatively highest level of effectiveness of internal audit as compared to extremely low level of competency (i.e strongly disagree category) at 1percent level of significance. Similarly, keeping other factors remain constant, a unit improvement in the agree competency level, we would expect a 3.857 improvement in the log odds of being in the relatively highest level of effectiveness of internal audit as compared to extremely low level of competency (i.e. strongly disagree category) at 1percent level of significance. In addition, holding other factors remain constant, a unit improvement in the neutral response competency level, we would expect a 2.5823 improvement in the log odds of being in the relatively highest level of effectiveness of internal audit as compared to extremely low level of competency (i.e strongly disagree category) at 5percent level of significance. In general, as response category switches from the lower competent level to that of higher competent level (which is strongly agree competent category), we observed an improvement in the internal audit effectiveness. This research result is consistent with the previous research of Internal Audit effectiveness (Albrecht et,al, 1988; vegans berg he 2005; Al-matarne2011).Similarly the results were obtained in other studies conducted in Ethiopian public sector offices (Shewamene, 2014) the internal audit staffs educational levels, the staff experience and continues training among the most important determinant of IA effectiveness.

The regression result for the independence of internal audit department were also significantly predicts effectiveness of internal audit, especially for the response category of agree and strongly agree as compared to the reference category, strongly disagree. A unit improvement in the agree response level for independence, we would expect a 5.366 improvement in the log odds of being in the relatively highest level of internal audit effectiveness as compared to extremely low level of independence (i.e. strongly disagree category) at 5percent level of significance, given all the other variables in the model are held constant. In the same way, holding other factors constant, a unit improvement in the strongly agree level independence, we would expect a 9.558 improvement in the log odds of being in the relatively highest level of internal audit effectiveness as compared to extremely low level of independence (i.e strongly disagree category) at 1percent level of significance. In general, internal audit effectiveness is responsive for relatively higher level of independence (i.e. for the response of strongly agree and agree category of auditors). The result of this research were reliable with the previous auditing research works of Schyf (2000) independency of internal audit are determined IAE and also research worked on south African public sector office(Alzeban and Gwilliam, 2014; Cohen, \& Sayag, 2010; Van Peursem, 2005; Mihret and Yismaw, 2007) they find that the independency of internal audit staffs was the critical determinants of internal audit effectiveness.

The regression results Shows that sufficient resources were also significantly predicts effectiveness of internal audit, especially for the response category of disagree and agree as compared to the reference category, strongly disagree. A unit increase in the disagree response level for sufficient resource, we would expect a 2.672 disimprovement in the log odds of being in the relatively highest level of internal audit effectiveness as compared to extremely low level of resources (i.e. strongly disagree category) at 10percent level of significance, given all the other variables in the model are held constant. Similarly, holding other factors constant, a unit increment in the agree response level of resource availability, we would expect a 4.588 dis-improvement in the log odds of being in the relatively highest level of internal audit effectiveness as compared to extremely low level of resources (i.e strongly disagree category) at 1percent level of significance. This result might be due to the fact that there might be underused of some available resources adjustment or budget transfer from internal audit department to other department might been done that is why in contradiction. This research results is contradict with the Previous research of IAE Alzeb et.al(2014), show that, if there are sufficient amount of both financial and human resources are allocated and hired the quality of internal audit performance will probably increase. Ali et.al (2007), Ahmed et al. (2009) for example, stated that the most intensive problem for internal audit is coping with lack of sufficient resources and hampered the effectiveness of organization and decreased the contribution of internal auditors.

The regression results for approved internal audit chart were significantly predicts effectiveness of internal 
audit, especially only for the response category of disagree as compared to the reference category, strongly disagree. Assuming all other variables in the model remain constant, a unit increase in the disagree response level for approved internal audit chart, we would expect a 9.201 dis-improvement in the log odds of being in the relatively highest level of internal audit effectiveness as compared to extremely low level of approved internal audit chart (i.e. strongly disagree category) at 10percent level of significance. This result might be due to the fact that the charter was not setting the right directions that means some important element like purpose, authority and responsibility under charter missed and also charter might not be periodically reviewed and that is why in contradiction. In addition, the result of this hypothesis was consistent with the prior audit researches conducted by (Peursem, 2005; O’Regan, 2002).

The variable Rship stands for the smooth relationship between internal and external auditors and significantly predicts effectiveness of internal audit, especially only for the response category of agree as compared to the reference category, strongly disagree. A unit improvement in the agree response level for smooth relationship between auditors, we would expect a 4.520 improvement in the log odds of being in the relatively highest level of internal audit effectiveness as compared to extremely low level of relationship (i.e. strongly disagree category) at 5percent level of significance, given all the other variables in the model are assumed to be constant. The result of this research was reliable with the previous auditing research conducted Almohaimeed, (2000). Brierley et al. (2001) demonstrated that proper participation can enhance productivity and adequacy of audits, and helps administration give higher quality administrations. Trouble in the middle of inner and external auditors is regularly perceived as a component harming the nature of both sorts of audit.

The coefficient for gender shows that as compared to male auditors, female auditors are more likely to improve internal audit effectiveness, and it's statistically significant at 5 percent of level of significance. Therefore, as we increase the number of female auditors by a one unit (in other hand, as we switch from male to female auditors), we expect a 1.862969 increase in the log odds of being in a strongly agree response level (relatively higher level) of internal audit effectiveness, given that all the other variables in the model are held constant.

\section{5. conclusions and recommendations \\ 5.1 Conclusions}

Broad-based growth, development and economic transformation, via enhancing the capacity and number of internal auditors, has been the major issue in various development strategies in Ethiopia, but still the quality and quantity of the auditors is as considerable agenda in Ethiopia. In addition, audit quality is a key tool in both public and private sector. It is necessary to maintain the quality of auditors because it helps to minimize problem in different sectors. This study provides empirical evidence on the factors affecting internal audit effectiveness by taking 118 sample of internal auditors from SNNP regional bureau. The study used both descriptive and econometric methods to analyze the data set. In particular, the econometric model is based maximum likelihood estimation technique of ordered logit model internal audit effectiveness as the dependent variable, which takes a categorical value from $1=$ strongly disagree to $5=$ strongly agree. Accordingly, the followings are the main findings of this study:

- Female auditors were more likely to improve internal audit effectiveness, and it's statistically significant at 5 percent of level of significance. Therefore, as the organization increase the number of female auditors by a one unit (in other hand, as we switch from male to female auditors), it is expected that at 1.862969 increase in the log odds of being in a strongly agree response level (relatively higher level) of internal audit effectiveness, given that all the other variables in the model are held constant. This result indicates that internal audit effectiveness is gender specific.

- The availability of competent employees and institutional structure is significantly predicts effectiveness of internal audit. This confirms that as the level of competency improves we expect an improvement in the internal audit effectiveness.

- Every internal auditor are taking actions, activities and decisions independently as of rules and regulations without interventions from their boss or else has a significant effect on internal audit effectiveness. In general, internal audit effectiveness is responsive for relatively higher level of independence (i.e. for the response of strongly agree and agree category of auditors).

- The availability of resources both human and material resources are also significantly predicts effectiveness of internal audit, especially for the response category of disagree and agree as compared to the reference category, strongly disagree. This result might be due to the fact that there might be underemployed employment of some available resources that is why in contradiction.

$\circ \quad$ The smooth relationship between internal and external auditors also significantly predicts effectiveness of internal audit, especially only for the response category of agree as compared to the reference category, strongly disagree. This indicates that smooth relationship between internal and external auditors improves internal audit effectiveness.

- The availability of standardized approved internal audit chart which describes every aspect related with 
internal audit is also significantly predicts effectiveness of internal audit, especially only for the response category of disagree as compared to the reference category, strongly disagree.

\subsection{Recommendation}

The findings of the study call for appropriate supportive interventions to improve the internal audit effectiveness in different governmental sectors in Ethiopia. Accordingly, the following recommendations were forwarded to improve the effectiveness of internal auditors:

- Since female auditors were more likely to improve internal audit effectiveness, and it's statistically significant at 5 percent of level of significance, the concerned body should give emphasis on capacity building program to male auditors in the form of education or/ and on job training opportunities.

$\circ \quad$ The concerned body should give emphasis for highly competent employees during the recruitment season of auditors in different sectors.

- Since the finding shows that as resource level increase, internal audit effectives become dis-improves. Hence, government should identify an optimal level of resource for each sector that optimizes internal audit effectiveness.

- According to the result smooth relationship between internal and external auditors significantly predicts effectiveness of internal audit. Hence, the government or the concerned body should develop a feasible environment guiding the relationship between internal and external auditors.

$\circ \quad$ Finally, the government or the concerned body should play its supportive supervision and enforcement interventions to the availability of standardized approved internal audit charts in each sector.

\section{Reference}

Al-Twaijry, A. A. M., Brierley, J. A. \&Gwilliam, D. R. (2004), “An Examination of the Relationship Between internal and external audit in the Saudi Arabian corporate sector":Managerial Auditing Journal, 19 (7), pp.929-45.

Alzeban A, Gwilliam D. (2014). Factors affecting the internal audit effectiveness: A survey of the Saudi public sector, J. Int. Account. Audit. Taxat. 23:74-86.

Arena, M. and Azzone, G. (2009), "Identifying Organizational Drivers of Internal Audit Effectiveness": International Journal of Auditing, Vol. 13, 43-60. B.N. Tandon, (2010), Practical Auditing: 14th edition, pp.112-15.

Balnaves M. and Caputi P. (2001), "Introduction to Quantitative Research Methods, an investigative approach": Sage Publications, London, Thousand Oaks and New Delhi.

Beasley, M. S., Clune, R., and Hermanson, D. R. (2008). The impact of enterprise risk management on the internal audit function. Journal of Forensic Accounting, pages $1\{20$.

Bou-Raad, G. (2000), "internal auditors and a value-added approach: the new business regime":Managerial Auditing Journal, 15(4), pp.182-186.

Charles et.al, 2014 International Journal of Economics, Finance and Management Sciences 2014; 2(2): 132-137 "Exploring internal auditor independence motivators: Kenyan perspective"

Chepkorir, L. (2014). Roles and Challenges of Internal Auditing in the private in company .MBA Projects.

Christopher, J., Sarens, G., \& Leung, P. (2009). A critical analysis of the independence of the internal audit function: evidence from Australia. Accounting, Auditing \& Accountability Journal, 22(2), 200-220. 50

Cohen A. \&Sayag, G. (2010), "the Effectiveness of Internal Auditing: An Empirical Examination of its Determinants in Israeli Organizations": Australian Accounting Review, 20(3), 296-307.

Coram P. Ferguson, C. and Moroney R. (2008), "Internal Audit, Alternative Internal Audit Structures and the Level of Misappropriation of Assets Fraud": Accounting and Finance, 48, pp.543-59.

Cronbach"es, L. J. (1951), "Coefficient alpha and the internal structure of tests": Psychometrika, 16, pp.297-334.

Dale, B.G. and Duncalf, A.J. 1985, „Quality-related Decision Making: A Study in Six British Companies"e, International Journal of Operations and Production Management, 5: 15-25.

Davidson, R., Goodwin-Stewart, J. and Kent, P. (2005), "Internal Governance Structures and Earnings Management", Accounting and Finance, 45(2), pp. 241-67.

Drent, D. (2002), "The duest for increased relevance: internal auditors who successfully communicate and balance their needs and those of their clients can increase their relevance to the organisation", Internal Auditor, Vol. 59 No. 1, pp. 49-54.

Eden D, M. (1996). Impact of Internal Auditing on Branch Bank Performance.

Ethiopian Construction Directory 2015/16 Budget year

Fernandez, S. and Rainey, H.G. 2006, „Managing Successful Organizational Change in the Public Sector ${ }^{\text {ee }}$, Public AdministrationReview, 66: 168-76.

Field A. (2009), Discovering statistics using SPSS, 3rd edition, SAGE. Publication ltd.

Flesher D. and Zanzig J. (2000), "Management accountants express a desire for change in the functioning of 
internal auditing": Managerial Auditing Journal, 15(7), 331-37.

Flynn, B.B., Schroeder, R.G. and Sakakibara, S. 1994, „A Framework for Quality Management Research and an Associated Measurement Instrument ${ }^{\mathrm{ee}}$, Journal of Operations Management, 11: 339-66.

Goodwin, J. (2004), "A comparison of internal audit in the private and public sectors", Managerial Auditing Journal, Vol. 19 No.5, pp.640-50.

Goodwin, J., \& P. Kent, 2003, Factors affecting the voluntary use of internal audit, Paper presented at the Annual Meeting of the American Accounting Association, Hawaii. 51

Government of Ethiopia (1961), "Auditor general proclamation": No. 179/1961, Negarit Gazette.

Green, W. (1997) Econometric Analysis. Upper Saddle River: Prentice Hall.

Holt, T., DeZoort, T. (2009), "The effects of internal audit report disclosure on investor confidence and decisions", International Journal of Auditing, No.March, pp.61-77.

How2statsa (2015) What is Cronbach's alpha

Johnson"s.(2006), "Should internal audit report to the CFO", CFO.com, No. October 13.

Leung, P. and Cooper, B.J. (2009), "Internal audit - an Asia-Pacific profile and the level of compliance with Internal Audit Standards": Managerial Auditing Journal, 24(9), pp.861-82.

Likert, R. (1932). A Technique for the Measurement of Attitudes. New York: Archives of Psychology.

Mihret, D. G. and Yismaw, A.W. (2007), "Internal audit effectiveness: an Ethiopian public sector case study": Managerial Auditing Journal, 22(5), 470-84.

Mihret, D.G. and Woldeyohanes, G. Z (2008), "Value-added role of internal audit: an Ethiopian case study": Managerial Auditing Journal, 23(6), 567-95.

Ministry of Finance and Economic Development (2004), Internal Audit Standards and Code of Ethics for Internal Auditors and Internal Audit Procedural Manual: Ministry of Finance and Economic Development.

Pallant, J. (2007), "SPSS survival manual”, 3rd ed. Sydney: Ligare Book Publisher.

Randal J.Elder, Marks S. Beasley and Alvin A. Arens (2008)

Reynolds, M.A. (2000), Professionalism, Ethical Codes and the Internal Auditor: A Moral Argumente, Journal of Business Ethics,(24), 115-24

Sarens G. and Beelde I.D. (2006), "The Relationship between Internal Audit and Senior Management, A Qualitative Analysis of Expectations and Perceptions”: International Journal of Auditing,10(3), 219 -41.

Sawyer, L.B. 1988, Sawyers' Internal Auditing, Institute of Internal Auditors, Altamonte Springs, FL.

ShewameneHailemariam, 2014 "determinants of internal audit effectiveness at public sectorin Ethiopia

Soh, D. and Bennie, M. (2011), "The internal audit function Perceptions of internal audit roles, effectiveness and evaluation": Managerial Auditing Journal, 26(7), 605-22.

Somekh, B and Lewinn, C. (2005), Research methods in the social sciences: London, SAGE Publications Ltd.

The institute of internal auditors (2001), 2004, 2009 and 2011 Standards for the Professional Practice of Internal Auditing (SPPIA): Audit Tools/NewIIAStandards.htm,

The Statement on Auditing Practice (SAP-6) of the Institute of Chartered Accountants of India 52

Van Gansberghe, C.N. (2005), Internal auditing in the public sector: a consultative forum in Nairobi, Kenya, shores up best practices for government audit professionals in developing nations", Internal Auditor, 62 (4), pp.6973.

Van Peursem, K. (2005), “Conversations with Internal Auditors: The Power of Ambiguity": Managerial Auditing Journal, 5, pp.489-512.

William C.Boynton, Raymond N.Johnson and Walter G.Kell (2002)

Woodard C.A (2002), Administerse Perceptions of Internal Auditing Roles and Effectiveness in Texas and Big Twelve Public Enterprises, Texas Southern University 


\section{Appendix}

Appendix B: Model assumption test results

Appendix I: Pairwise correlation for explanatory variables

\begin{tabular}{r|rrrrrrr} 
& comptenc & Indepen Resource & Rship & mgtsupp Apprvc t & gender \\
\hline comptenc & 1.0000 & & & & & & \\
Indepen & 0.4186 & 1.0000 & & & & & \\
Resource & 0.4036 & 0.4734 & 1.0000 & & & & \\
Rship & 0.5178 & 0.5559 & 0.5911 & 1.0000 & & & \\
mgtsupp & 0.3561 & 0.4378 & 0.4614 & 0.5754 & 1.0000 & & \\
Apprvchrt & 0.4428 & 0.4561 & 0.3250 & 0.3539 & 0.4355 & 1.0000 & \\
gender & -0.1215 & 0.0171 & 0.1163 & 0.0590 & -0.1295 & 0.0368 & 1.0000 \\
age & 0.0948 & 0.1614 & 0.0567 & 0.1222 & 0.1414 & 0.1701 & 0.0476 \\
Expr & 0.0886 & 0.0105 & -0.0242 & -0.0115 & -0.0708 & -0.0298 & 0.0936 \\
Educ & 0.0707 & 0.0572 & -0.0503 & 0.1161 & 0.2348 & -0.1103 & -0.0279
\end{tabular}

\begin{tabular}{r|rrr} 
& age & EXpr & Educ \\
\hline age & 1.0000 & & \\
EXpr & 0.6563 & 1.0000 & \\
Educ & 0.1638 & 0.0123 & 1.0000
\end{tabular}

Appendix II: White's test for heteroskedasticity

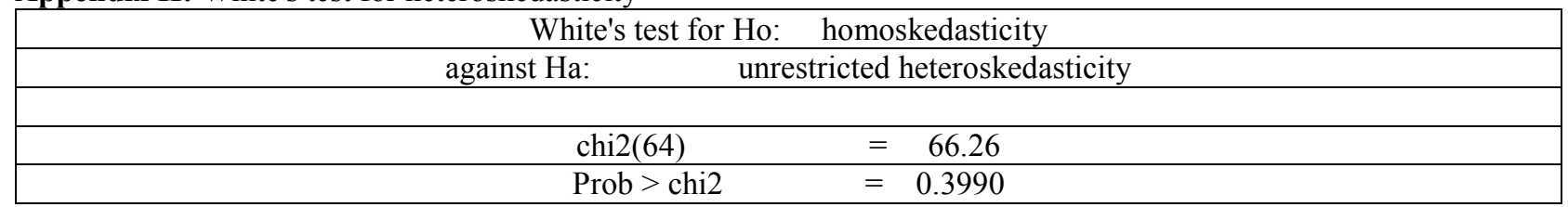

Appendix III: Ramsey RESET test for omitted variables

\begin{tabular}{|l|l|}
\hline Ramsey RESET test using powers of the fitted values of Iaditeffecv \\
\hline & Ho: model has no omitted variables \\
\hline & $\mathrm{F}(3,104)=1.63$ \\
\hline & Prob $>\mathrm{F}=0.1868$ \\
\hline
\end{tabular}

